\title{
Formation of Silicon Carbide Using Volcanic Ash as Starting Material and Concentrated Sunlight as Energy Resource
}

\author{
Kensuke Nishioka, Junki Komori, Kouji Maeda, Yasuyuki Ota, \\ Hiroshi Kaneko, and Kosei Sato
}

Faculty of Engineering, University of Miyazaki, 1-1 Gakuen Kibanadai Nishi, Miyazaki 889-2192, Japan

Correspondence should be addressed to Kensuke Nishioka; nishioka@cc.miyazaki-u.ac.jp

Received 8 January 2015; Accepted 20 March 2015

Academic Editor: Raghu N. Bhattacharya

Copyright (C) 2015 Kensuke Nishioka et al. This is an open access article distributed under the Creative Commons Attribution License, which permits unrestricted use, distribution, and reproduction in any medium, provided the original work is properly cited.

\begin{abstract}
$\mathrm{SiC}$ was formed using volcanic ash as starting material and concentrated sunlight as energy resource. The solar furnace was composed of two parts: Fresnel lens and reacting furnace. The reacting furnace was composed of a cylindrical vacuum chamber and quartz glass plate functioning to guide the concentrated sunlight into the furnace and was placed at the focal point of the Fresnel lens. The sample was made from the mixture of silica formed from volcanic ash and graphite and placed in the carbon crucible inside the reacting furnace. The temperature in the carbon crucible reached more than $1500^{\circ} \mathrm{C}$. After the reaction using concentrated light, $\beta$-SiC was formed. The weight $\%$ of formed $\mathrm{SiC}$ was $90.5 \%$.
\end{abstract}

\section{Introduction}

Growing interest in silicon carbide $(\mathrm{SiC})$ has arisen from the need for electronic devices that are capable of operating at high power levels, high temperatures, and hostile environments. $\mathrm{SiC}$ is a wide band-gap semiconductor and ensures high temperature stability and is also characterized by large breakdown fields [1-4]. $\alpha$ - and $\beta$-SiC are the major polytypes of $\mathrm{SiC}$. The hexagonal polytypes of $2 \mathrm{H}-, 4 \mathrm{H}$-, and $6 \mathrm{H}-\mathrm{SiC}$ are classified as $\alpha$-SiC. The cubic type of $3 \mathrm{C}-\mathrm{SiC}$ is categorized as $\beta$-SiC. These crystal structures have an important role in application of $\mathrm{SiC}$ to own different physical properties $[1,2]$. The reaction of $\alpha$-SiC production by silica with carbon is shown by the following equation:

$$
\mathrm{SiO}_{2}+3 \mathrm{C} \longrightarrow \mathrm{SiC}+2 \mathrm{CO}(\mathrm{g})
$$

Regarding the reaction of $\beta$-SiC, production is given by the following equations:

$$
\begin{aligned}
& \mathrm{SiO}_{2}+\mathrm{C} \longrightarrow \mathrm{SiO}+\mathrm{CO}(\mathrm{g}) \\
& \mathrm{SiO}+2 \mathrm{C} \longrightarrow \mathrm{SiC}+\mathrm{CO}(\mathrm{g})
\end{aligned}
$$

In industry, $\alpha$ - and $\beta$-SiC powders are mainly produced by a carbothermic reaction of silica and carbon at temperatures greater than $2200^{\circ} \mathrm{C}$ and $1500^{\circ} \mathrm{C}$, respectively [5-8]. It is an energy intensive process. In this process, the high purity silicon dioxide $\left(\mathrm{SiO}_{2}\right)$ and infinite energy for high temperature are needed.

In order to prepare the high purity $\mathrm{SiO}_{2}$ from unexplored feedstock, we used volcanic ash as a starting material. A kind of volcanic ashes called "Shirasu," abundantly deposited due to a big pyroclastic flow in Southern Kyushu, Japan, is one of the unused natural resources. In our previous work, we have successfully formed high purity $\mathrm{SiO}_{2}$ from Shirasu with a simple process $[9,10]$.

In order to generate the high temperature, we used concentrated sunlight as an energy source for the formation of SiC. The solar furnace can produce high temperature in a short period of time by utilizing optical systems as a sunlight concentrator. Through this method, a new production process to create materials that require to be produced under high temperature condition with regard to the shortage of energy resources has been significantly provided [11-14].

There is no report which forms the semiconductor material of high value like $\mathrm{SiC}$ by using environment-friendly 


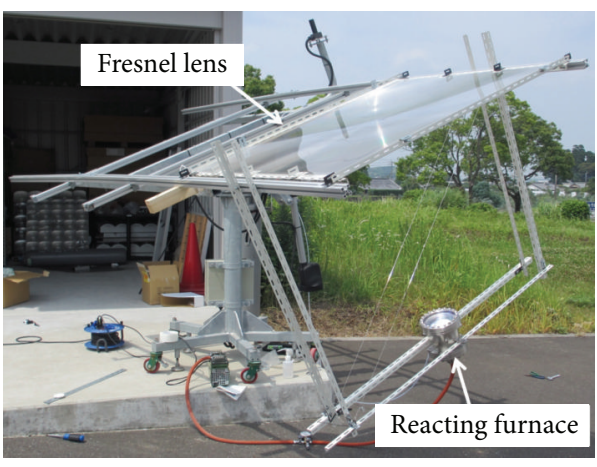

(a)

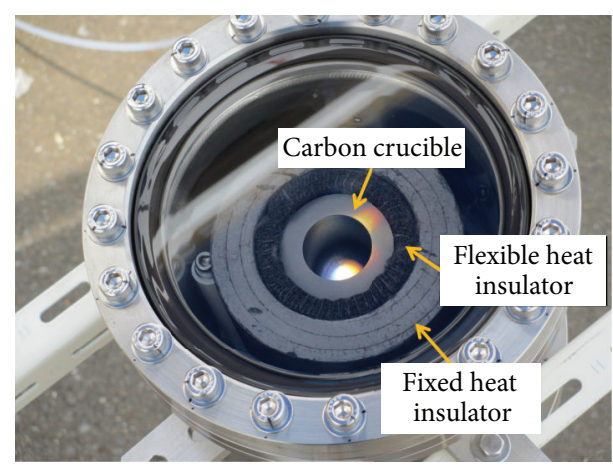

(b)

Figure 1: Solar furnace system. As shown in (a), the solar furnace was composed of two parts: Fresnel lens and reacting furnace. The carbon crucible was covered with heat insulators to keep the crucible's high temperature, as shown in (b).

concentrated sunlight. In this study, we prepared a $\mathrm{SiC}$ using the solar furnace that produces an ultrahigh temperature condition by utilizing a Fresnel lens as a sunlight concentrator.

\section{Experimental}

Figure 1 shows the solar furnace used in this study. As shown in Figure 1(a), the solar furnace was composed of two parts: Fresnel lens and reacting furnace. The material of the Fresnel lens used in this study was polymethyl methacrylate (PMMA), and it had the area of $1.40 \mathrm{~m} \times 1.05 \mathrm{~m}$. The reacting furnace was composed of a cylindrical vacuum chamber (diameter: $20.45 \mathrm{~cm}$ and depth: $14.3 \mathrm{~cm}$ ) and quartz glass plate functioning to guide the concentrated sunlight into the furnace and was placed at the focal point of the Fresnel lens. The carbon crucible was covered with heat insulators to keep the crucible's high temperature, as shown in Figure 1(b). The solar furnace traced the sun to keep the Fresnel lens normal to the sun. For the sun tracking, an automatic sun tracker (Green Source Technology, GST-200) was used.

The sample used in this study was made from the mixture of silica formed using Shirasu volcanic ash and graphite and placed in the carbon crucible inside the reacting furnace. The high purity nanoporous silica was fabricated using Shirasu volcanic ash as a starting material. The materials with Shirasu were melted at $1400^{\circ} \mathrm{C}$. A mother glass was formed by quenching the melt in pure water. Leaching was performed by immersing the mother glass into a hydrogen chloride $(\mathrm{HCl})$ solution. Nonsilica phases formed by phase separation in the mother glass were leached out with acid solution. The obtained porous silica was more than $99 \%$ pure $[9,10]$.

After that, the air inside the reacting furnace was discharged so that it will be in vacuum condition with the pressure of $0.1 \mathrm{MPa}$. The Ar gas was then flowed into the reacting furnace until it reached the atmospheric pressure. Next, the sample was irradiated with the high concentrated sunlight for 3 hours while the Ar gas kept on flowing at $31 / \mathrm{min}$ into the reacting furnace. After the irradiation process, the furnace was left until the sample cooled down to room temperature under Ar atmosphere. Finally, the sample was

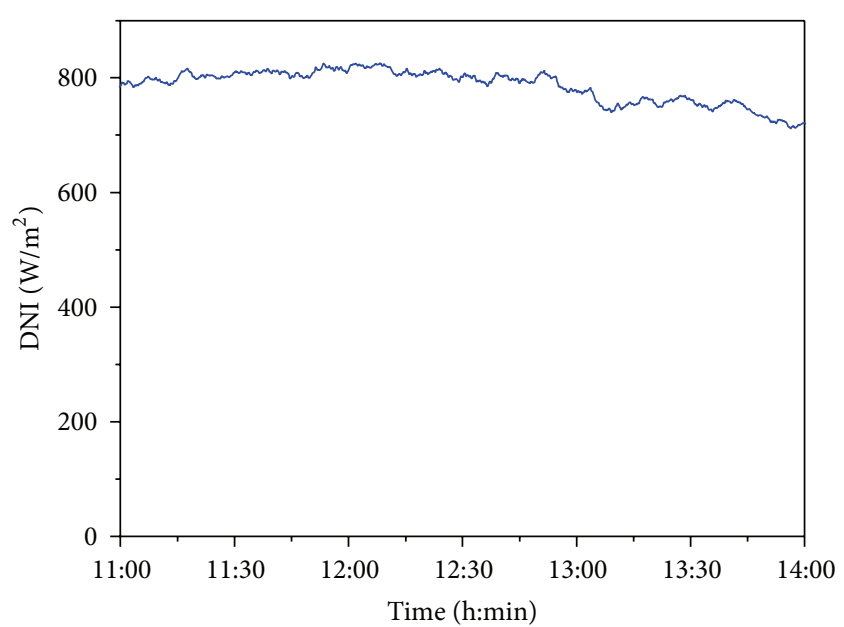

FIGURE 2: Direct normal irradiance (DNI) when the sample was irradiated with the high concentrated sunlight.

evaluated by X-ray diffraction (XRD, PANalytical, X'Pert PRO) and Raman spectroscopy (SPEX, 1877).

\section{Results and Discussion}

The solar furnace system used the Fresnel lens to collect sunlight and focused it onto the reacting chamber. The system can only use the direct beam component of sunlight. Figure 2 shows direct normal irradiance (DNI) when the sample was irradiated with the high concentrated sunlight. DNI during the experiment was stable and high. Since the solar furnace is equipped with the sun tracking system, temperature of the furnace depends on the intensity of DNI. Therefore, it is necessary to use a stable and high DNI.

Figure 3 shows XRD patterns of the sample before and after the irradiation process. Through the XRD analysis before irradiation, the pattern showed only diffraction peaks from graphite (C). From this result, the silica that had been prepared by using Shirasu volcanic ash was proved to be noncrystalline. On the other hand, the result of XRD analysis 


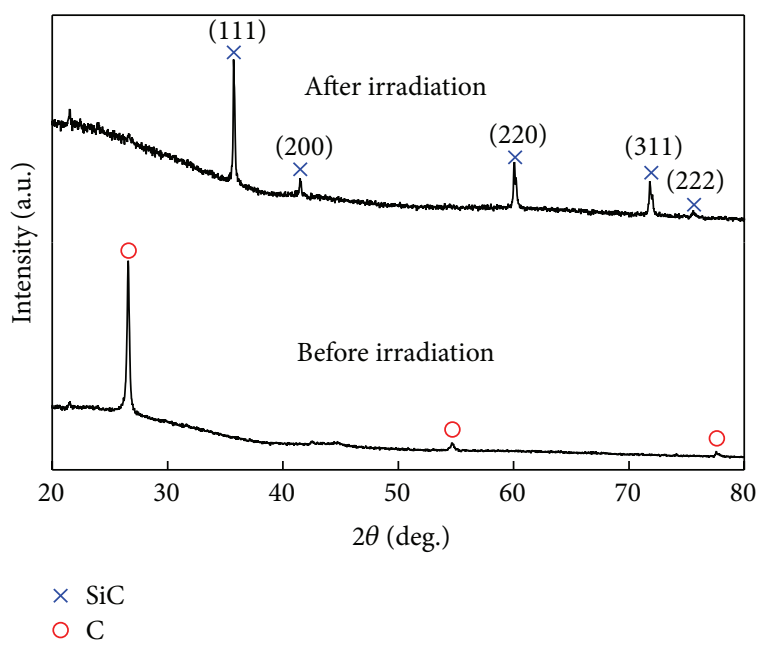

Figure 3: X-ray diffraction patterns of samples before and after irradiation process of concentrated sunlight.

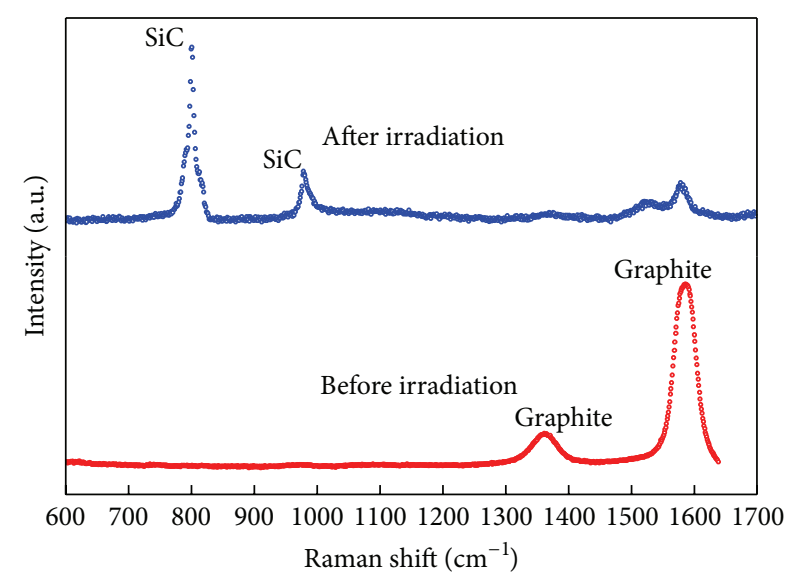

FIGURE 4: Raman spectra of samples before and after irradiation process of concentrated sunlight.

after irradiation confirmed that five diffraction peaks, which were not seen in the result before irradiation, appeared. The diffraction peak labeled with (111) was the characteristic of $\mathrm{SiC}(\alpha-$ or $\beta-\mathrm{SiC})$, while the other peaks labeled with (220), (311), (200), and (222) were based on $\beta$-SiC [15]. From XRD results, the sample was found to have produced the $\beta$-SiC component. As mentioned in the introduction, the temperature higher than $1500^{\circ} \mathrm{C}$ is needed for the formation of $\beta$-SiC. It is found that the temperature in the carbon crucible reaches more than $1500^{\circ} \mathrm{C}$.

Figure 4 shows the result of Raman spectra analysis of the sample before and after the irradiation process. The result before irradiation showed only two peaks due to graphite (C). On the other hand, in the Raman spectra after irradiation, two strong peaks were observed. The peak at $978 \mathrm{~cm}^{-1}$ is assigned to longitudinal optical (LO) phonon peak of $\mathrm{SiC}$, and the other at $798 \mathrm{~cm}^{-1}$ is assigned to transverse optic (TO) phonon peak reported by Feldman et al. [16]. Small peaks around $1540 \mathrm{~cm}^{-1}$ and $1590 \mathrm{~cm}^{-1}$ are assigned to $\mathrm{SiO}_{2}$ and the remaining graphite, respectively. The noncrystalline $\mathrm{SiO}_{2}$ in the sample before irradiation was crystallized by the high temperature. This Raman spectrum's results also indicated that $\mathrm{SiC}$ was formed in the sample after the irradiation process.

The quantitative determinations of the irradiated portion of the sample were carried out by calibration curves derived from XRD analysis to clarify the $\mathrm{SiC}$ content. First, standard specimens were made from mixture of $\mathrm{SiC}$ and raw materials $\left(\mathrm{SiO}_{2}\right.$ and $\left.\mathrm{C}\right)$ in different weight ratios \%. Those standard specimens were measured, respectively, by XRD analysis. From peak area ratios $\left[\mathrm{SiC}_{\text {area }} /(\mathrm{SiC}+\mathrm{C})_{\text {area }}\right]$ of $\mathrm{SiC}$ and $\mathrm{C}$ and weight ratios $\%\left[\mathrm{SiC}_{\mathrm{Wt}} /(\mathrm{SiC}+\mathrm{C})_{\mathrm{Wt}} \%\right]$ of $\mathrm{SiC}$ and $\mathrm{C}$, the calibration curves were obtained. From the result of the calibration curves it was found that $\mathrm{SiC}_{\mathrm{Wt}} /(\mathrm{SiC}+\mathrm{C})_{\mathrm{Wt}} \%$ of the sample after irradiation process was $90.5 \%$.

Previously, $\mathrm{SiC}$ was produced by the equipment which used electric power as energy source. For the formation of $\mathrm{SiC}$, the high temperature over $1500^{\circ} \mathrm{C}$ is needed and the energy consumption of these methods is high $[7,8]$. In this study, we used solar energy as energy source and SiC was successfully formed with the high temperature evolved from concentrated sunlight. The method implemented in this study could effectively avert the shortage of energy resources by using renewable energy.

\section{Conclusion}

We prepared $\mathrm{SiC}$ from volcanic ash using the solar furnace, which has never been performed before. The solar furnace was composed of two parts: Fresnel lens and reacting furnace. The sample was made from the mixture of $\mathrm{SiO}_{2}$ formed from volcanic ash and graphite and placed in the carbon crucible inside the reacting furnace. The XRD and Raman spectra indicated that $\mathrm{SiC}$ was formed in the sample after the irradiation process. The type of the $\mathrm{SiC}$ was $\beta$-type (3C-SiC). It is expected to be the valid utilization method with volcanic ash as the natural resource, to form superior materials using renewable energy.

\section{Conflict of Interests}

The authors declare that there is no conflict of interests regarding the publication of this paper.

\section{Acknowledgment}

A part of this work was supported by INAMORI FOUNDATION.

\section{References}

[1] H. Morkoç, S. Strite, G. B. Gao, M. E. Lin, B. Sverdlov, and M. Burns, "Large-band-gap SiC, III-V nitride, and II-VI ZnSebased semiconductor device technologies," Journal of Applied Physics, vol. 76, no. 3, pp. 1363-1398, 1994.

[2] R. J. Iwanowski, K. Fronc, W. Paszkowicz, and M. Heinonen, "XPS and XRD study of crystalline 3C-SiC grown by sublimation method," Journal of Alloys and Compounds, vol. 286, no. 1-2, pp. 143-147, 1999. 
[3] G. A. Slack and S. F. Bartram, "Thermal expansion of some diamondlike crystals," Journal of Applied Physics, vol. 46, no. 1, pp. 89-98, 1975.

[4] G. A. Slack and R. I. Scace, "Nitrogen incorporation in SiC," The Journal of Chemical Physics, vol. 42, no. 2, pp. 805-806, 1965.

[5] B. Zhao, B. Yang, T. Wang et al., "Nanocarbon-dependent synthesis of one-dimensional bead-chain-like $\beta$-SiC," Powder Technology, vol. 246, pp. 487-491, 2013.

[6] S. Sugiyama and M. Togaya, "Phase relationship between 3Cand $6 \mathrm{H}$-silicon carbide at high pressure and high temperature," Journal of the American Ceramic Society, vol. 84, no. 3-12, pp. 3013-3016, 2001.

[7] B. M. Moshtaghioun, R. Poyato, F. L. Cumbrera et al., "Rapid carbothermic synthesis of silicon carbide nano powders by using microwave heating," Journal of the European Ceramic Society, vol. 32, no. 8, pp. 1787-1794, 2012.

[8] S. Raygan, B. Kondori, and H. M. Yangijeh, "Effect of mechanical activation on the production of SiC from silica sand," International Journal of Refractory Metals and Hard Materials, vol. 29, no. 1, pp. 10-13, 2011.

[9] K. Sato, T. Kokubu, and K. Nishioka, "Effect of heat treatment on high purity nanoporous silica formed from volcanic ash deposit shirasu," Advanced Materials Research, vol. 747, pp. 547-550, 2013.

[10] K. Sato, T. Kokubu, and K. Nishioka, "Control of pore size of high purity nanoporous silica formed from volcanic ash deposit shirasu," Advanced Materials Research, vol. 622-623, pp. 970974, 2013.

[11] A. A. Abdurakhmanov, U. F. Turaeva, and S. I. Klychev, "Methodology of determining integral radiant emittance of solar radiation receivers," Applied Solar Energy, vol. 45, no. 2, pp. 114-115, 2009.

[12] T. P. Salikhov, V. V. Kan, E. M. Urazaeva, T. V. Savatyugina, and G. M. Arushanov, "Prospects for application of superdispersed powders obtained in small solar furnaces to form ceramic membranes," Applied Solar Energy, vol. 47, no. 2, pp. 146-148, 2011.

[13] R. Kh. Rakhimov, R. A. Muminov, and T. T. Riskiev, "Application of functional ceramics synthesized in a large solar furnace for the synthesis of complex compounds," Applied Solar Energy, vol. 48, no. 1, pp. 47-50, 2012.

[14] S. A. Faiziev, M. S. Paizullakhanov, E. Z. Nodirmatov, R. Y. Akbarov, and M. A. Zufarov, "Synthesis of pyroxene pyroceramics in large solar furnace with $\mathrm{ZrO}_{2}$ crystallization nucleator," Applied Solar Energy, vol. 44, no. 2, pp. 139-141, 2008.

[15] T. Takeshita, Y. Kurata, and S. Hasegawa, "Bonding properties of glow-discharge polycrystalline and amorphous Si-C films studied by x-ray diffraction and x-ray photoelectron spectroscopy," Journal of Applied Physics, vol. 71, no. 11, pp. 5395-5400, 1992.

[16] D. W. Feldman, J. H. Parker, W. J. Choyke, and L. Patrick, "Phonon dispersion curves by raman scattering in SiC, polytypes 3C, 4H, 6H, 15R, and 21R," Physical Review, vol. 173, no. 3, pp. 787-793, 1968. 

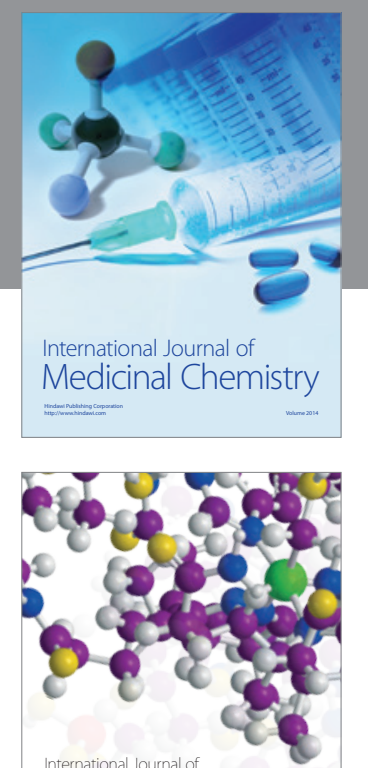

\section{Carbohydrate} Chemistry

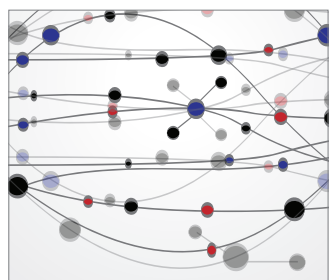

The Scientific World Journal
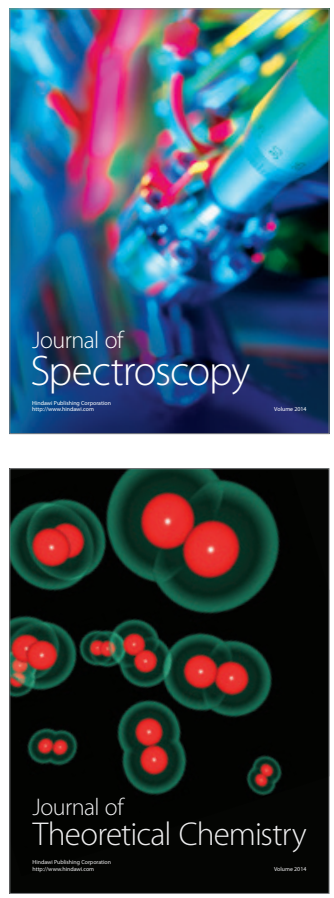
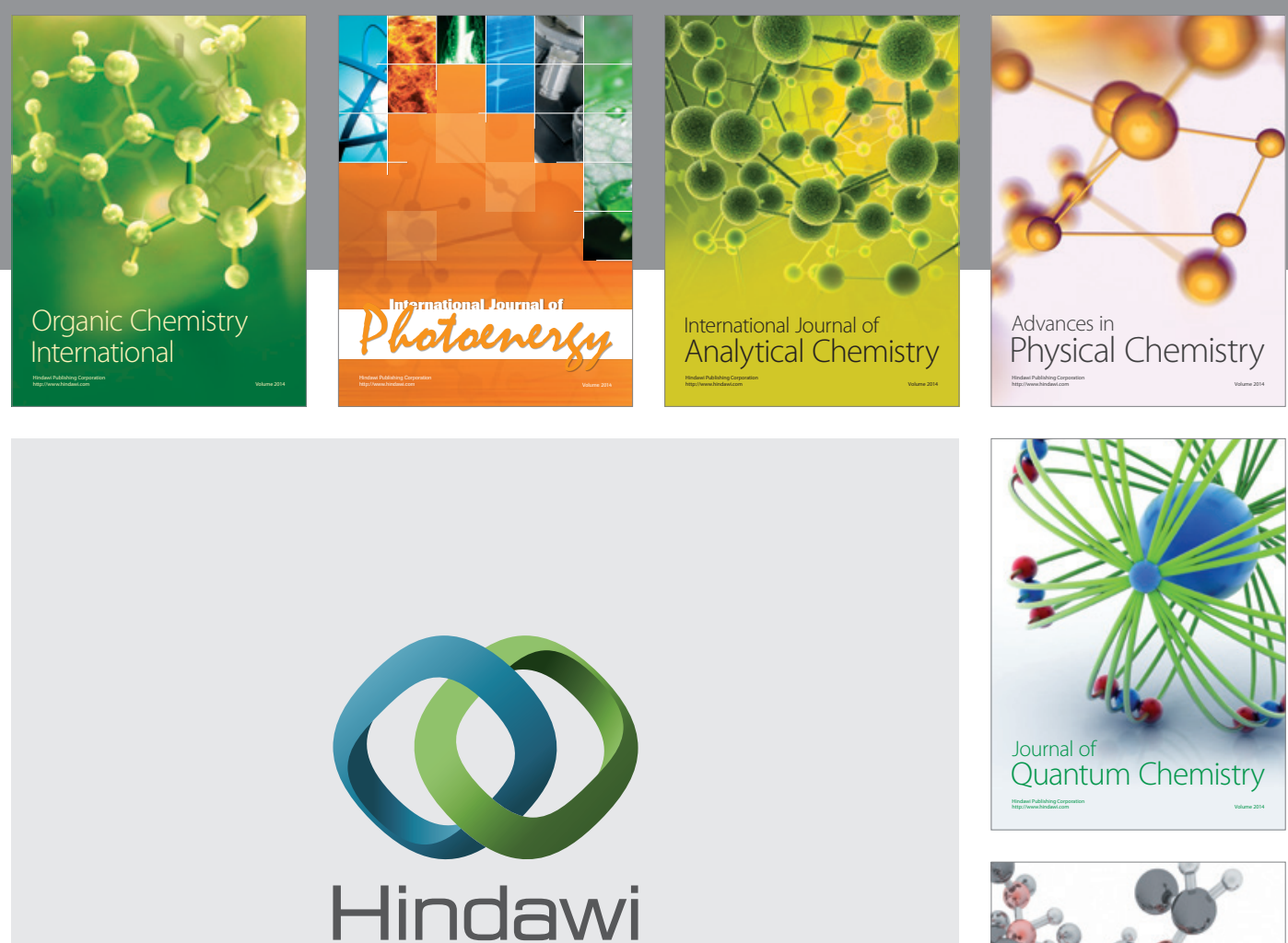

Submit your manuscripts at

http://www.hindawi.com

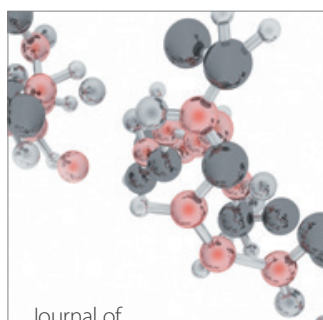

Analytical Methods

in Chemistry

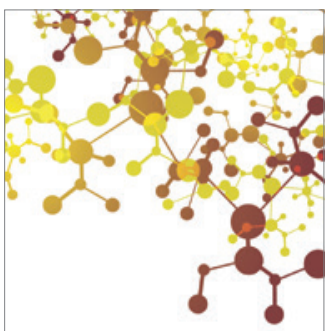

Journal of

Applied Chemistry

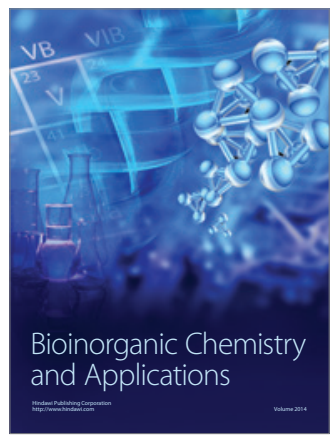

Inorganic Chemistry
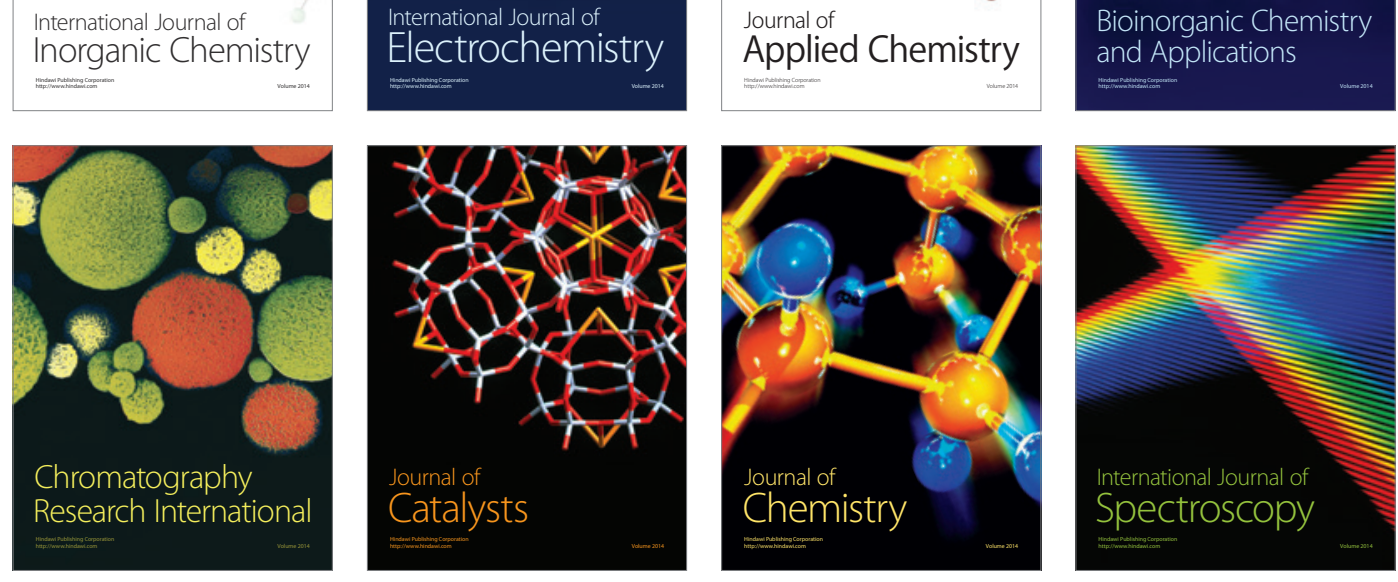